\title{
Thermal and Mechanical Response of Partially Protected Steel I-Beam under Fire
}

\author{
Muhammad Imran ${ }^{1, *}$, Mohd Shahir Liew ${ }^{1}$, Mohammad Shakir Nasif ${ }^{2}$, \\ Enrique Munoz Gracia ${ }^{3}$, Kamaluddeen Usman Danyaro ${ }^{4}$, and Muhammad Usama Niazi ${ }^{2}$ \\ ${ }^{1}$ Department of Civil and Environmental Engineering, Universiti Teknologi PETRONAS 32610 Seri \\ Iskandar, Perak, Malaysia \\ ${ }^{2}$ Department of Mechanical Engineering, Universiti Teknologi PETRONAS 32610 Seri Iskandar, \\ Perak, Malaysia \\ ${ }^{3}$ MMI Engineering, UK \\ ${ }^{4}$ Offshore Engineering Centre, Universiti Teknologi PETRONAS, Perak, Malaysia
}

\begin{abstract}
Offshore and onshore structures continuously experience hydrocarbon fire accidents almost every year. To secured structure against extreme fire conditions, passive fire protection (PFP) is applied. However, PFP is a costly material which is applied only on critical structural members. Any unprotected surface can cause major structural damages during fire incidence if the behaviour of an unprotected surface is unknown. Usually, PFP applied easily around the column, but for beams, the application varies with the beam locations. In this paper the behaviours of steel beam compared with three different common scenarios such as fully protected, unprotected and partially protected under hydrocarbon fire. Fully protected beam has tremendous fire resisting capability compared to partially protected beams or unprotected beams. The study revealed that temperature of the top flange in partially protected beam exceeds more $600^{\circ} \mathrm{C}$ in less than 10 minutes which caused rapid failure in less than 30 minutes. Under extreme fire conditions the strength and stiffness of a beam affected which cause instability of structure during fire accident.
\end{abstract}

\section{Introduction}

Hydrocarbon fire accidents are common in the Oil and Gas (O\&G) industry due to several processes related activities [1-4]. The most recent incident occurred on $4^{\mathrm{TH}}$ December 2015 at Azeri platform, 63 workers were on board only 33 were rescued. The rescue operation was affected due to bad weather and fire continued several days [5, 6]. Secondly, PEMEX Abkatun A processing platform where a gas leak, followed by hydrocarbon fire took the lifes of four worker several were injured and caused structural damage as shown in Fig. 1 [7]. Therefore, the necessity to maintain structure stability during fire is to minimize damages to structure and live losses during an accidents [8]. The Passive fire protection (PFP) materials are the best solution to maintain structure integrity during accident which maintained

\footnotetext{
*Corresponding authors: shahir_liew@utp.edu.my, engrimran_ce@hotmail.com
} 
structural temperature below critical range. Normally columns are protected from all sides which is less critical element compared to beams-column connections and partially unprotected beams supports top slab $[1,6]$.

Under normal composite construction steel beam exposed from three sides. The normal thermal response of fire in composite construction such as convection and radiation effects initiated from the web and bottom flange. Whereas, the top flange hides under concrete slab, fall celling or steel deck etc., which heated at the end. When the top flange covers during fire the temperature of bottom flange and web experienced highest temperature gradient. But when bottom flange and web is protected then the temperature of top flange received highest heat flux from the graded steel deck. The details about conditions are not discussed in existing literature and design codes such as Eurocode 3.

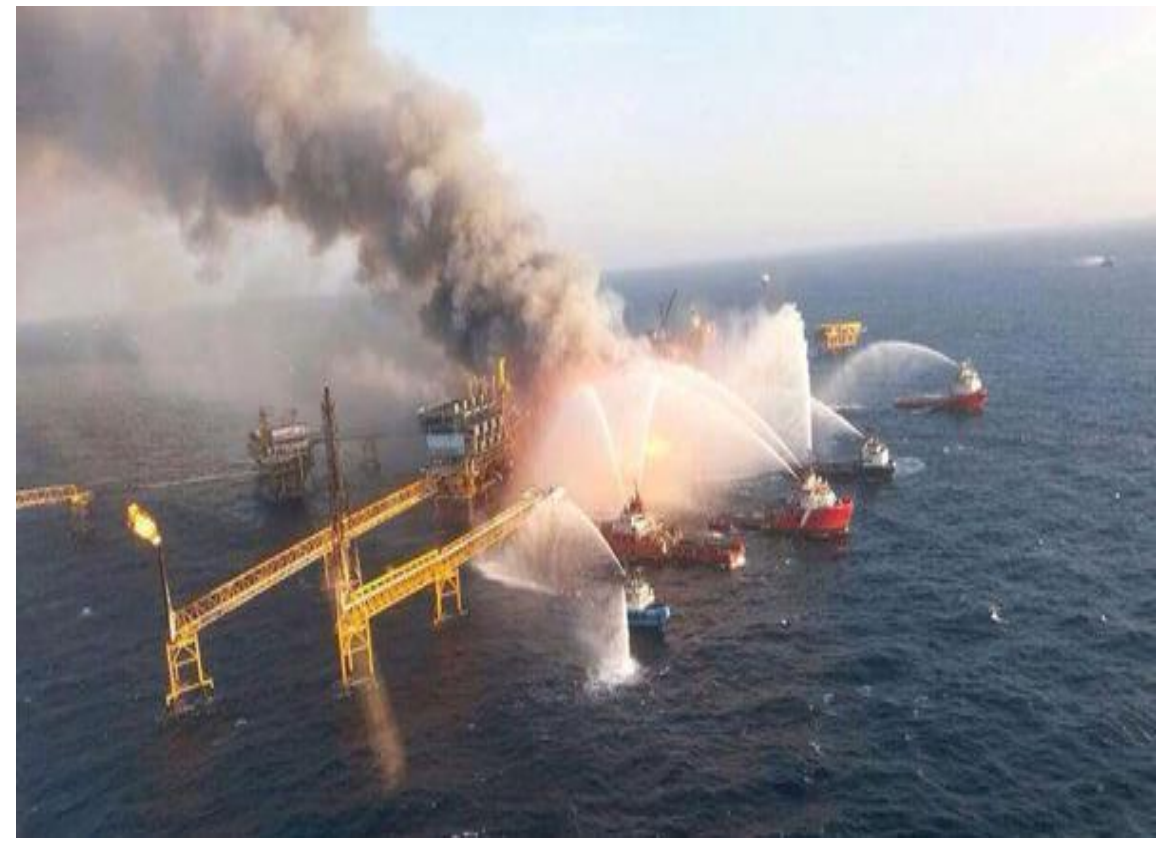

Fig.1. PEMEX Accident 2015 [7]

Therefore, in this paper, the details of PFP under various scenarios discussed based on available experimental studies conducted by various researchers. Secondly, nonlinear finite element analysis has been presented to highlight the significance of partially protected beams in designing $\mathrm{O} \& \mathrm{G}$ structures.

\section{Behaviour of beams under elevated temperature}

\subsection{Unprotected beam}

The mechanical properties of start steel losing as the temperature exceed more than $400^{\circ} \mathrm{C}$ according to Eurocode 3. After $400{ }^{\circ} \mathrm{C}$ steel the mechanical properties are considered to contribute nothing and continue to deform shown in Fig. 2 [9]. However exposed vs protected surface to fire is a major factor that directly affects internal stability of a beam.

There are numerous studies previously conducted by researcher in order to understand the behavior of steel beams by heating up beams from three sides [10,11]. An experiment was under cellulosic fire which has shown that the modulus of elasticity was effected as 
temperature rose to $400{ }^{\circ} \mathrm{C}$ and failure occurred in between $650^{\circ} \mathrm{C}-750^{\circ} \mathrm{C}$ [12]. To avoid rapid failure PFP applied to reduce fire effects and delay failure time.
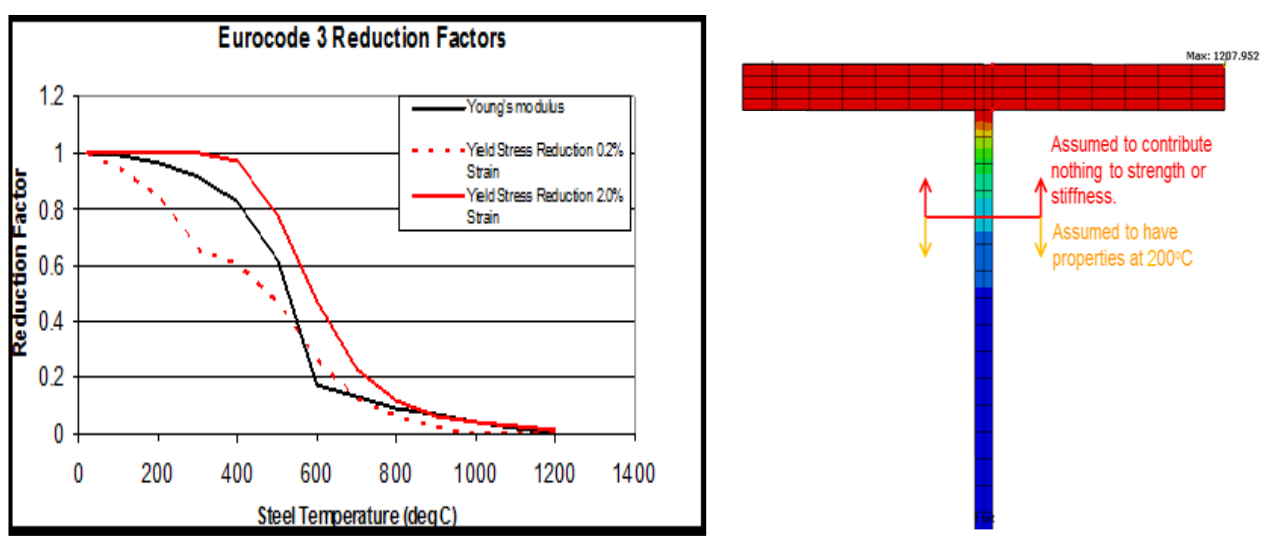

Fig.2. Mechanical properties of steel after $400^{\circ} \mathrm{C}$ and Thermal Gradient [9]

\subsection{Effective use of passive fire protection (PFP)}

In older days sand and cement mixture were used as a fireproofing material. These materials provided fire to resist more than three hours [13]. But these protection can only resist cellulosic fire and increase additional load due by increasing section size. Whereas, Hydrocarbon fire released extremely high temperature compared to normal fire. Cement usually exploded under high temperature as moisture rapidly transformed into vapour. Latest fireproofing or PFP materials are the best solution for maintaining structure integrity during a fire accident without increasing section size and weight. PFP such as intumescent paints are developed by combining flame retarders such as acid source (ammonium polyphosphate \& APP), carbon source (Pentaerythritol \& PER) and blowing agents (Melamine \& MEL) [14]. These coatings creates a thermal barrier when exposed to high temperature by developing intumescent char layers. PFP maintained structural integrity by resisting heat contact direct to steel.

However, applying PFP is a costly operation and required deep understanding before optimized application on a member. Normally, columns are protected from all sides unlike beam section which are difficult to protect from all sides due to fall-celling, grated slab, secondary beams or stiffeners. Since the operation is expensive, therefore only selected members are protected after intensive analysis and simulation of various fire scenarios. Improper use of PFP can not only cause significant operation cost but also affects structural stability.

\subsection{Effects of partial fire proofing}

There are numerous studies available that focused on different parameters steel beams tested with three side protection. Effects partially or single sided protection cause severe strength and stiffness losses and unpredicted failure. Failure mode is also depends on the exposed surface area to fire. Ghojel and Wong (2005) conducted a study on heat transfer model to predict the temperature gradient on steel I beam. The top flange was embedded in the concrete and web and bottom flange was exposed to fire [11]. The unprotected web normally exposed to a constant temperature. Constant temperature caused web buckling and caused premature failure. Wang et al. (2014) compared FE modelling on three sides heated cellular composite 
steel beam under ISO834 standard fire. The temperature at the web is relatively higher compared to bottom flanges and lowest at the top flange due to heat loss from the concrete slab. The web heated and transferred excessive amount non uniform heat to top and bottom flange [15].

A partial fire protection causes heat to penetrate into the section from unprotected surface and cause instability of beam. The temperature distribution on the web is almost uniform when exposed to fire [11]. The increment in fire protection coating thickness enhances the fire resistance capability of beam. Partially protected by a thicker protection layer reduced temperature gradient on the web [16]. Research discovered that web heated up more rapidly compared to top and bottom flange. Hence, the web is the major source of heat transfer to top flanges. After comparing the results with code requirements author claimed that European design code can accurately predict web and bottom flange temperature but due to complex thermal boundary condition it provides high predication for top flange.
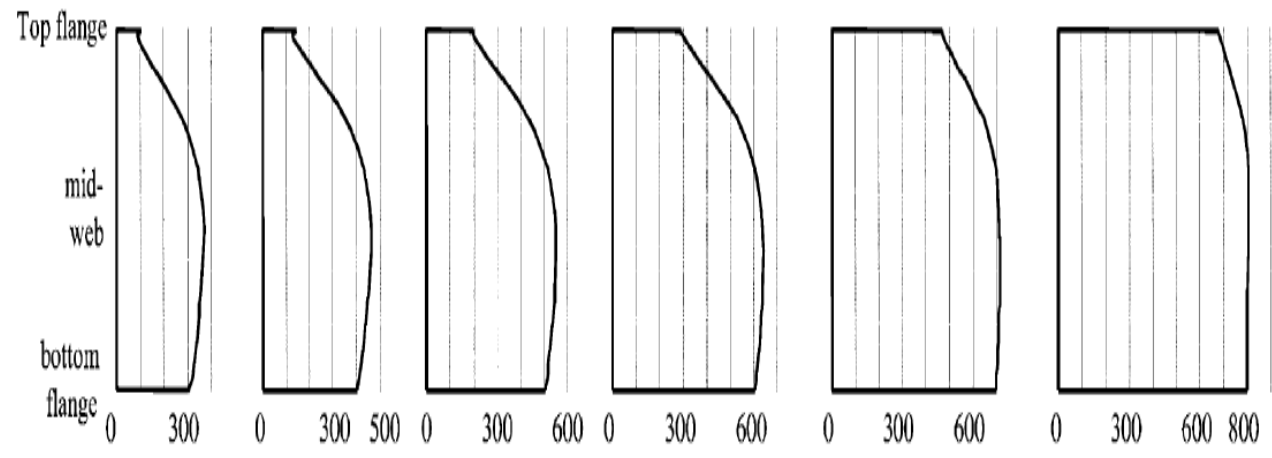

\section{Temperature $\left({ }^{\circ} \mathrm{C}\right)$}

Fig. 3. Temperature distribution between web top and bottom flange [17]

Another behavior was reported by [17], when beam tested under ISO384 standard fire temperature. During the test top flange was protected by the PFP to prevent damage to load cell. The temperature gradient on the protected top flange rose slowly compared to unprotected the bottom flange and the web. Temperature initially rose much more slowly as shown in Fig. 3. When the burner switched off the heat conduction continued to top flange until difference reduced from $300^{\circ} \mathrm{C}$ to $100{ }^{\circ} \mathrm{C}$ as shown in Fig. 3 .

It was also noticed that heat into the top flange continued rise within the protected surface. On the other hand, temperature of the protected surface reduce more slowly compared to unprotected surface [17].

The common cases in the O\&G industry is by leaving top flange unprotected due to placement of pipes and grating on a beam which caused premature failure of a steel beam. Castle and Castle (1987) examine the effect of fire under such condition theoretically when a top flange remain unprotected [13]. Author suggested that neglecting the effect of the top flange unprotected viable under normal fire conditions.

But under hydrocarbon fire temperature the effects could be sever which instantly affects the mechanical properties of the steel. Therefore, it is required special design consideration which was neglected in most of the studies. In this paper fully \& partially protected beams compared with unprotected (top flange) beam under the hydrocarbon fire by FE modelling technique to compare the possible behaviour of the beam under accidental hydrocarbon fire loads. 


\section{Thermal and static analysis}

To perform thermal analysis for the beams typical properties of Universal Beam Section UB $457 \times 152 \times 52$ were used with the span of $4240 \mathrm{~mm}$ as shown in Fig. 4. Three steel loaded beams were modelled with total static load of $40 \mathrm{kN}$ at L/4, (10 kN per node). Effects of fire \& PFP was considered during thermal analysis using Fire and Heat Transfers Simulation (FAHTS) and static loading with FEM using Ultimate Strength for Offshore Structure (USFOS). The beams were modelled with following boundary conditions:

1. Unprotected

2. Fully protected and

3. Three sided protected (unprotected from top flange).

Standard hydrocarbon temperature / heat flux was applied using predefined common HC fire using FAHTS. These fire loads were then transferred to USFOS for nonlinear FE analysis by considering transient mechanical properties of steel under static and thermal loading. The FAHTS used shell element while USFOS consider line element by default. Nevertheless, in USFOS the beams can also model as a shell element which gives more accurate results but computational time is higher than line element and results are more or less same [18].

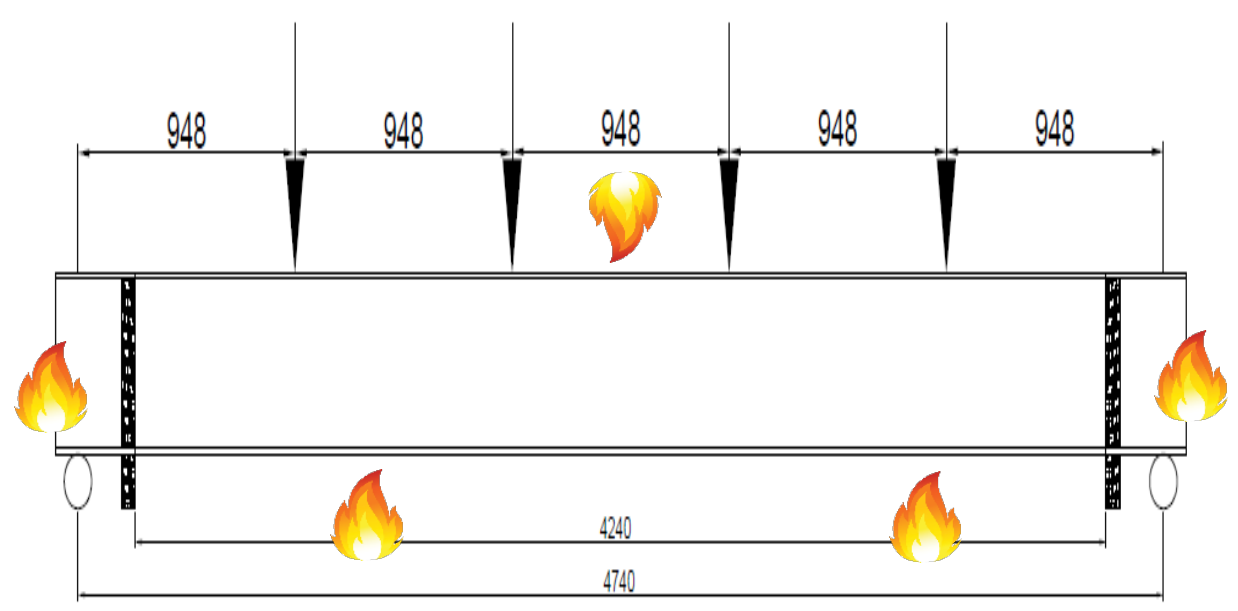

Fig. 4. Beam Model Details of Applied loading

\section{Results \& discussion}

Comparison is discussed in two parts (a) thermal analysis temperature vs time curve and (b) nonlinear response for loaded beam under fire load with deflections vs time curve.

\subsection{Thermal response}

The comparison of three different types of beams under hydrocarbon fire clear shown the variation in temperature. For unprotected beam, the web, top flange and bottom flange almost followed the hydrocarbon fire curve as radiation and conduction is high. Typically, beam having a ratio of a large surface area to volume cools down more quickly than a section having a small ratio. The web heat up faster than the top and the bottom flanges which caused steel section to deform more rapidly. In case of unprotected beam the web possessed high exposed surface area which heat up section quickly. The beam temperature increased $400^{\circ} \mathrm{C}$ 
in 3 minutes as shown in Fig 5 (a) and after 6 minutes exceeds $800^{\circ} \mathrm{C}$ as shown in Fig 5 (b). The top flange, web and bottom flange have more or less same temperature as shown in Fig 6 . The smallest variation in delays was recorded due to heat conduction in section as shown in Fig. 6.

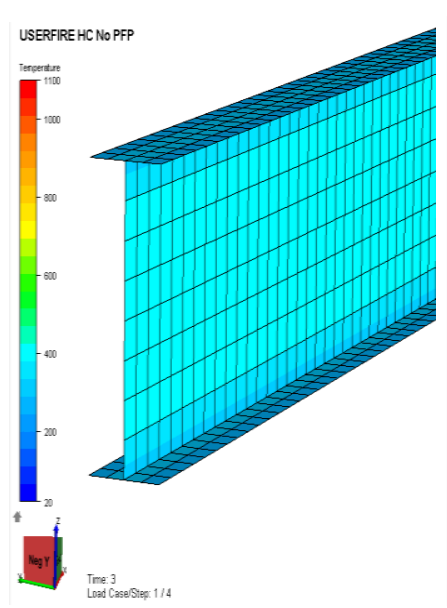

(a)

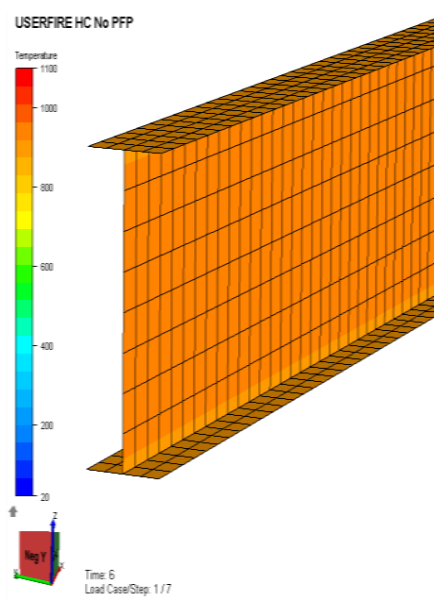

(b)

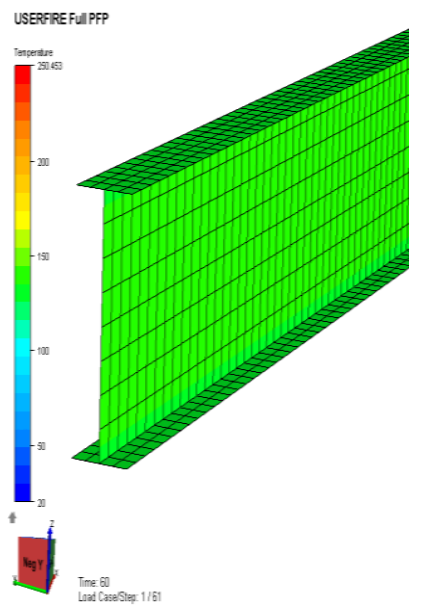

(c)

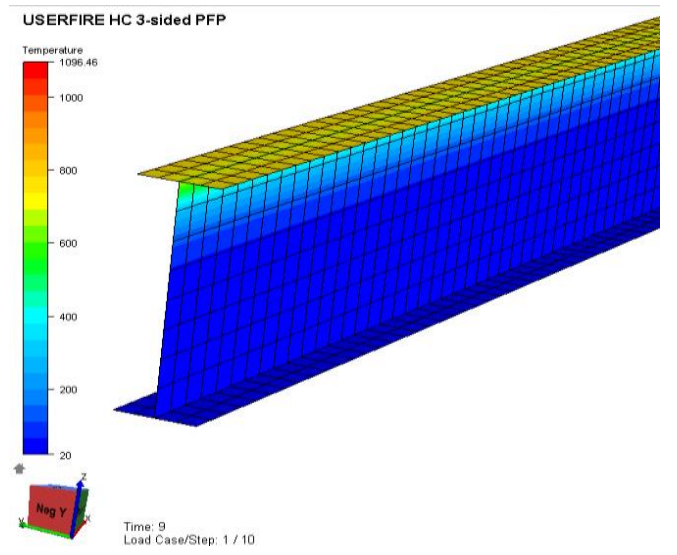

(d)

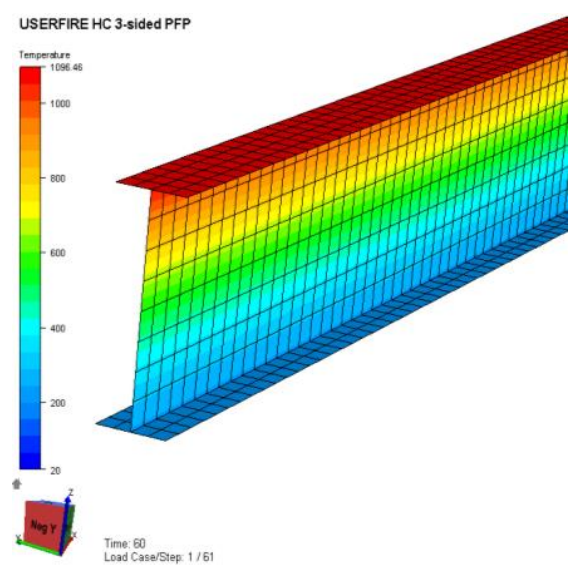

(e)

Fig. 5. (a) Temperature distribution on unprotected beam after 3 minutes (b) after 6 minutes (c) Temperature distribution on fully protected beam after 60 minutes (d) Temperature distribution on 3 sides protected beam after 9 minutes and (e) Temperature distribution on 3 sides protected beam after 60 minutes

In contrast, fully protected beam resisted temperature to propagate and maintain temperature below $400{ }^{\circ} \mathrm{C}$ for 2 hours as shown in Fig 7. Due to fully protection the top \& bottom flanges and the web exhibited was almost uniform temperature gradient though out section. Fully protected beam has tremendous fire resisting capability. After an hour beam temperature was below $200{ }^{\circ} \mathrm{C}$ as shown in as shown in Fig 5 (c) and Fig 7. 


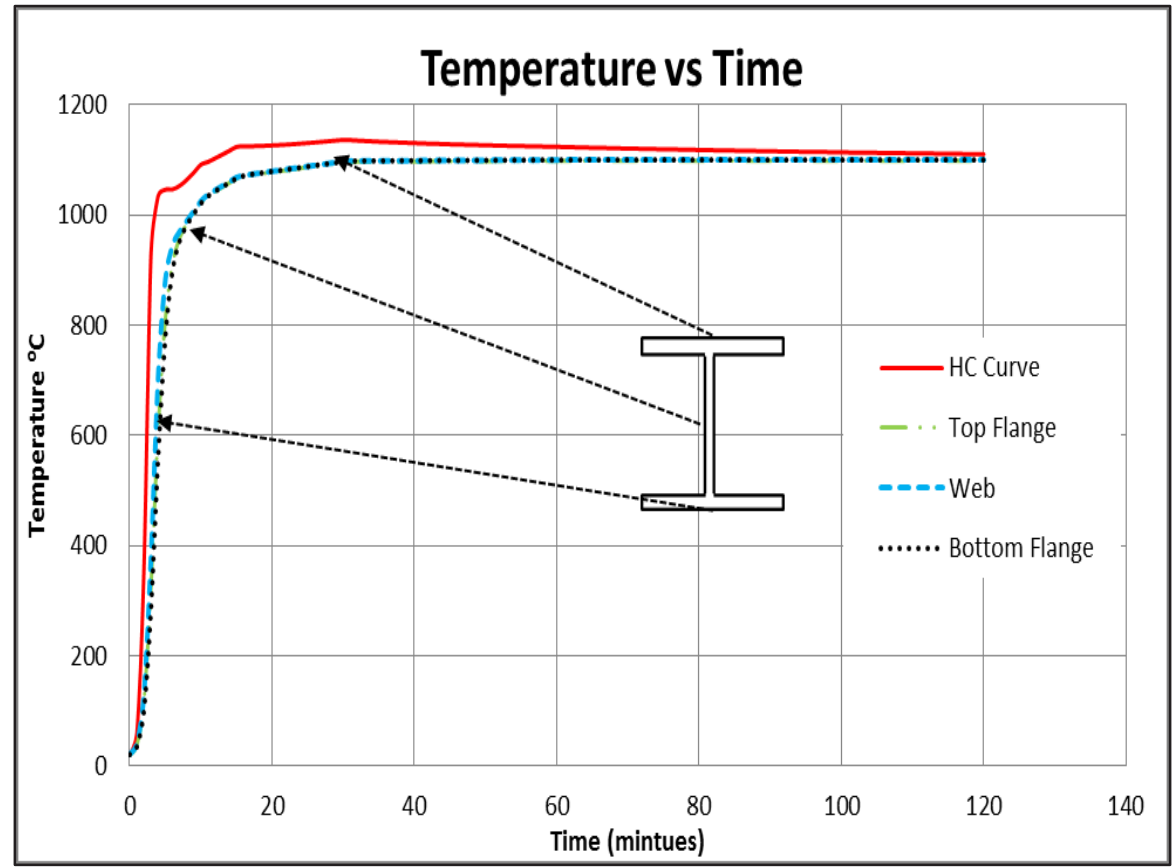

Fig. 6. Temperature vs time curve distribution of unprotected beam

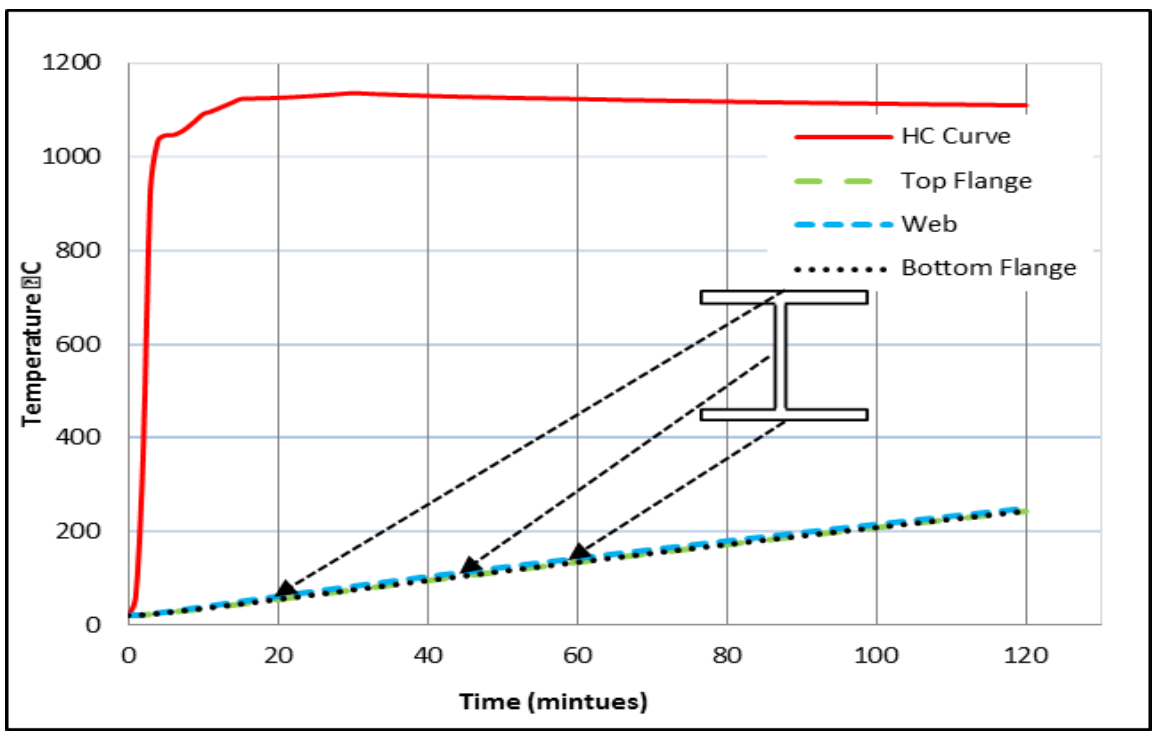

Fig. 7. Temperature vs time curve distribution of fully protected beam

On the other hand, three sided protected beams exhibited different behaviour as shown in Fig 8. Top unprotected flange was exposed to high temperature from top face and heated rapidly compare to the web as shown in Fig 5 (d) and Fig 8. The temperature of the web reached $400{ }^{\circ} \mathrm{C}$ after 40 minutes and after an hour web temperature rose to $600{ }^{\circ} \mathrm{C}$ as shown in Fig 5 (e). The lowest temperature was recorded on the bottom flange which was heated up slowly through conduction from the top flange to the web. 


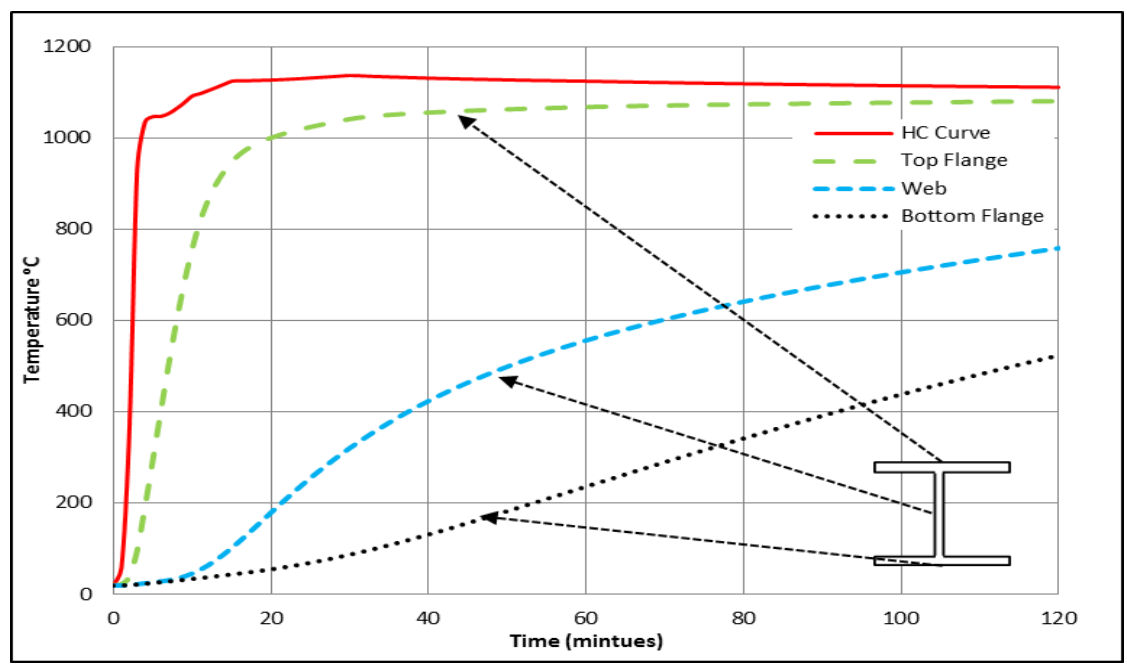

Fig. 8. Temperature vs time curve for three side protected beam

\subsection{Mechanical response \& failure modes}

PFP is an expensive material to apply and maintain. The deep understanding about the failure mode can be helpful for PFP on a beam. As discussed earlier, according to codes, mechanical properties are assumed to contribute nothing if the temperature exceeds more than $400{ }^{\circ} \mathrm{C}$. Normally, elastic modulus of steel is affected by $50 \%$ as the temperature of steel exceeds $500{ }^{\circ} \mathrm{C}$.

The behaviour of an unprotected beam started with deformation as temperature increased to $400{ }^{\circ} \mathrm{C}$ and rapid deformation observed after 4 minutes as the temperature exceeded $600{ }^{\circ} \mathrm{C}$ as shown in Fig 9. As discussed in Section 2 where under normal fire experimental, beam failed just in an hour. But under hydrocarbon fire the temperature was so intensive that beam completely failed in less than 6 minutes. This shown the significance of PFP application and understand behaviours of PFP under extreme fire conditions for petrochemical industry.

The comparison is therefore necessary between fully protected and partially or three sided protected beams. The behaviour deflection verse time for fully protected was uniform beam started deform after 50 minutes of fire exposure. Deformation accelerated after an hour till failure occurred as defection exceeded span/20 after $+/-90$ minutes of fire exposures shown in Fig 10. 


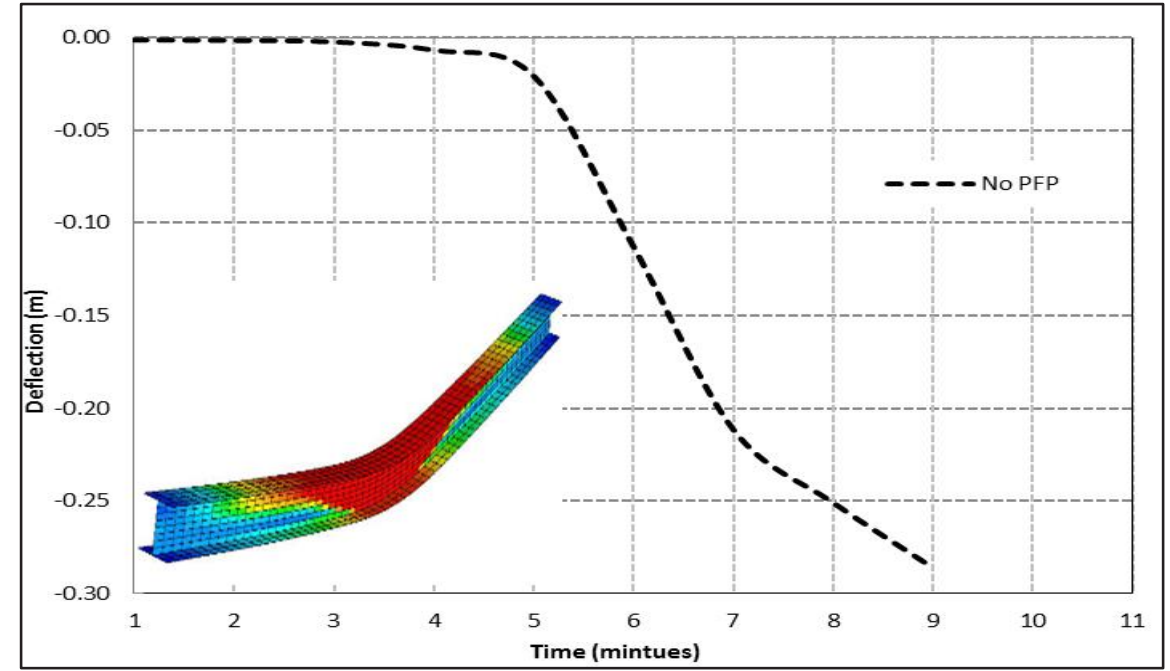

Fig.9. Deflection vs time curve for unprotected beam

The three sided protected beams on the other hand, deformed initially as behaviour changed from sagging to small amount of hogging after 25 minutes of fire exposure. Suddenly, tensile stresses were formed due to high temperature at top flange which caused minor hogging. As the temperature of top flange exceeded to $600{ }^{\circ} \mathrm{C}$, the beam started bending again and rundown deflection was observed. This behaviour was due to rapid temperature increment at the top flange which caused sudden thermal expansion as shown in Fig 11 and suddenly rundown deflection observed.

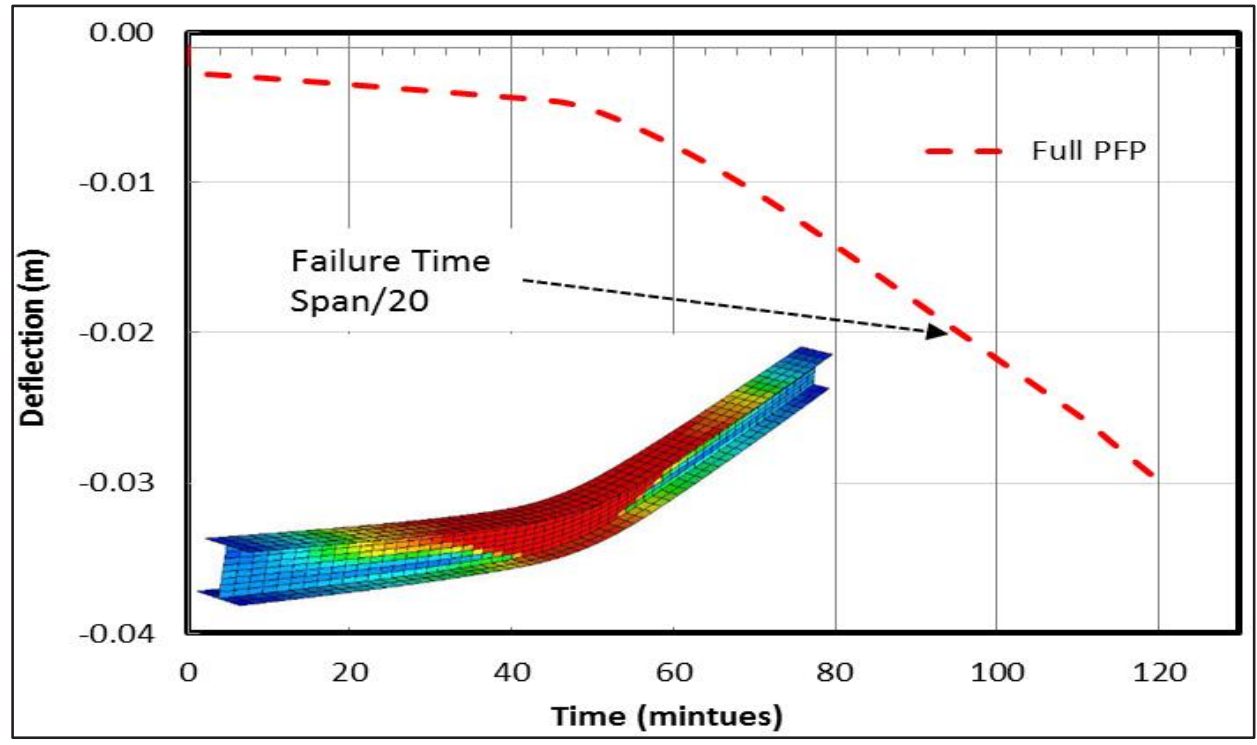

Fig. 10. Deflection vs time curve for fully protected beams 


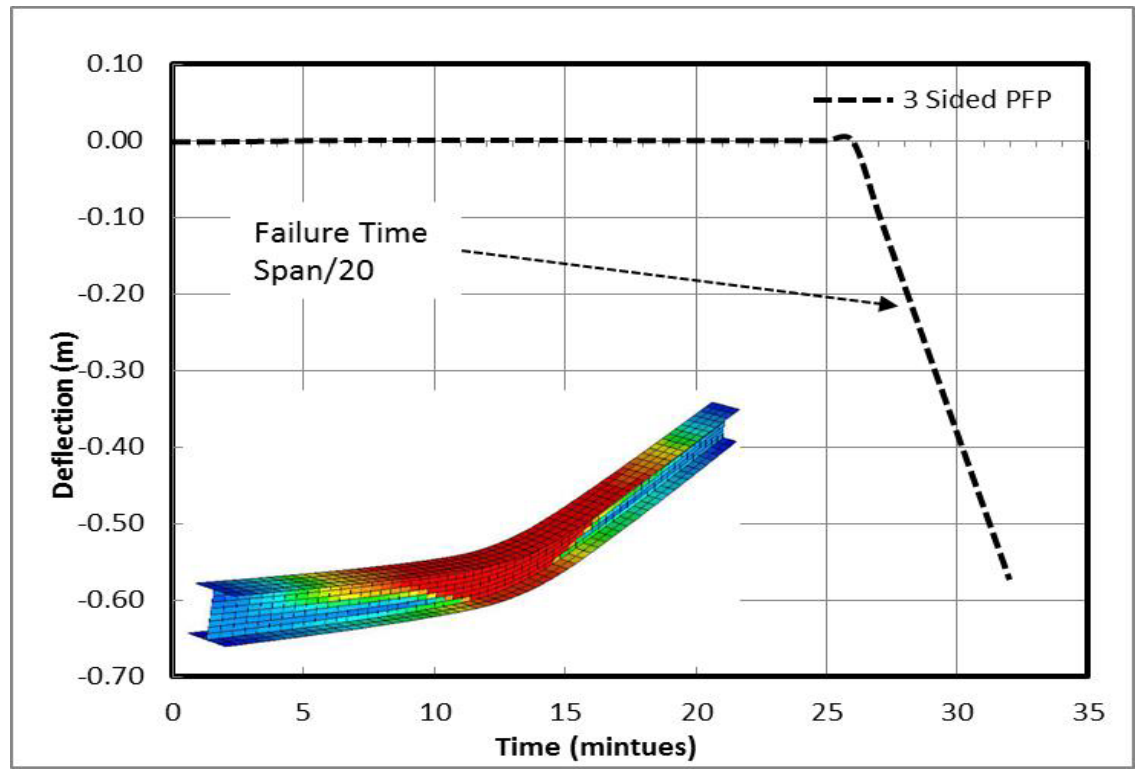

Fig.11. Deflection vs time curve for three side protected beams

\section{Conclusion}

The application of three-sided protection on a beam required special consideration. The present study is conducted to highlights the effect of three sided protected beams compared with and without full protection. Based on the analysis the following concluding remarks have been drawn:

- Fully protected beams can resist fire and maintain structural integrity for selected period of time.

- Unprotected steel lost mechanical properties as the temperature exceeded above $400{ }^{\circ} \mathrm{C}$, and failed as the temperature reached between $600{ }^{\circ} \mathrm{C}$ to $800{ }^{\circ} \mathrm{C}$. Under hydrocarbon fire the steel beam fail rapidly.

- Similarly, hydrocarbon fire rapidly deteriorates the strength \& stiffness of threesided protected beams. Such response of the beam during a fire accident could be dangerous for high pressure pipelines and fire escape routes.

- The partially protected steel continued to transfer heat from unprotected surface to protected surface. Under ordinary fire condition unprotected top flange can be neglected, but under hydrocarbon fire the effect should consider in order to maintain structural integrity.

- Further investigation is needed to validate FEM results. Therefore, the author is currently conducting an experimental study to validate model and further investigate parametric studies.

The author would like to thank MOHE for financial support for this project Cost Centre FRGS 0153AB-K85 (FRGS/1/2015/TK01/UTP/02/4), PROMAT and Universiti Teknologi PETRONAS for the graduate assistantship. 


\section{References}

1. M. Imran, M. S. Liew, and M. S. Nasif, "Experimental Studies on Fire for Offshore Structures and Its Limitations: A Review," Chemical Engineering, vol. 45, pp. 19511956, 2015 (2015).

2. U. M. Niazi, M. S. Nasif, M. Bin Muhammad, and M. Imran, "Modeling of Pool Fire and Injury Prediction Considering Different Wind Speeds and Directions in Offshore Platform," ARPN Journal of Engineering and Applied Sciences, Article vol. 11, no. 22, pp. 13000-13005, (2016).

3. M. Imran, M. S. Liew, M. S. Nasif, U. M. Niazi, and A. Yasreen, "Hydrocarbon Fire and Explosion's Safety Aspects to Avoid Accident Escalation for Offshore Platform," in ICIPEG 2016, M. Awang, B. M. Negash, N. A. Md Akhir, L. A. Lubis, and A. G. Md. Rafek, Eds. Singapore: Springer Nature Singapore, 2017, pp. 801-808, (2016).

4. M. Dadashzadeh, F. Khan, K. Hawboldt, and P. Amyotte, "An integrated approach for fire and explosion consequence modelling," Fire Safety Journal, vol. 61, pp. 324-337, (2013)

5. N. Bagirova, "One worker killed, 30 missing after Azeri oil rig fire: government," in REUTERS, ed. U.S: Thomson Reuters, (2015).

6. M. Imran, M. Liew, E. Garcia, M. Nasif, A. Yassin, and U. Niazi, "Deformation and Heat Transfer on Three Sides Protected Beams under Fire Accident," in IOP Conference Series: Earth and Environmental Science, 2018, vol. 140, no. 1, p. 012122: IOP Publishing,(2018).

7. Reuters, "Fire Out at Pemex Processing Platform," in gCaptain, ed, 2015.

8. M. Imran, M. S. Liew, M. S. Nasif, U. M. Niazi, and A. Yasreen, "Hazard Assessment Studies on Hydrocarbon Fire and Blast: An Overview," Advanced Science Letters, Article vol. 23, no. 2, pp. 1243-1247, (2017).

9. H. Smith, A. Sari, and Y. Ayhan, "Advanced Analysis Methods for Complex Structural Fire Assessment Problems," in Offshore Technology Conference, 2013: Offshore Technology Conference, (2013).

10. F. Wald et al., "Experimental Behaviour of a Steel Structure under Natural Fire," Fire Safety Journal, vol. 41, no. 7, pp. 509-522, 10// (2016).

11. J. Ghojel and M.-B. Wong, "Three-sided heating of I-beams in composite construction exposed to fire," Journal of Constructional Steel Research, vol. 61, no. 6, pp. 834-844, (2005).

12. C. Shuping, L. Shuting, and D. Yuli, "Experimental Investigation Of Behavior Of Simple Supported Steel Beams Under Fire," Journal of Southeast University (Natural Science Edition), vol. 35, p. S1, (2005).

13. G. Castle and G. Castle, "Effect of Fireproofing Design on Thermal Performance of Horizontal Members with Top Flange Exposed," Plant/Operations Progress, vol. 6, no. 4, pp. 193-198, (1987).

14. M. C. Yew and N. H. Ramli Sulong, "Fire-Resistive Performance of Intumescent FlameRetardant Coatings for Steel," Materials \& Design, vol. 34, pp. 719-724, 2// (2012).

15. X. D. Wang, L. Zhu, and P. J. Wang, "Temperature Distributions of Protected Cellular Composite Beams Heated Three Sides," in Applied Mechanics and Materials, 2014, vol. 578, pp. 184-187: Trans Tech Publ. (2014). 
16. P. Wang, X. Wang, M. Liu, and L. Zhang, "Web-post buckling of fully and partially protected cellular steel beams at elevated temperatures in a fire," Thin-Walled Structures, (2015).

17. T. C. H. Liu, M. K. Fahad, and J. M. Davies, "Experimental Investigation of Behaviour of Axially Restrained Steel Beams in Fire," Journal of Constructional Steel Research, vol. 58, no. 9, pp. 1211-1230, 9// 2002, (2002)..

18. M. Friebe, B.-S. Jang, and Y. Jim, "A parametric study on the use of passive fire protection in FPSO topside module," International Journal of Naval Architecture and Ocean Engineering, vol. 6, no. 4, pp. 826-839, (2014). 